\title{
Development and Effects Analysis of The Decentralized Rainwater Management System by Field Application
}

\author{
Han, Young $\mathrm{Hae}^{*} \cdot$ Lee, Tae Goo ${ }^{* *}$ \\ *Eco-Arche Institute of Ecological Urban Design \& Architecture, Jecheon-City Chungbuk, South Korea (youngseahan@nate.com) \\ ** Corresponding author, Semyung University, Depart.of Architecture Engineering, Jecheon-City Chungbuk, South Korea (tg_lee@semyung.ac.kr)
}

\section{A B STR A C T}

In this study, we developed a modular rainwater infiltration system that can be applied for general purposes in urban areas to prepare for localized heavy rain caused by climatic change. This study also analyzed the system's effects on reducing runoff. An analysis of the system's effects on reducing runoff based on rainfall data and monitoring data obtained between September 2012 and December 2013 after the system was installed showed that approximately $20 \sim 22 \%$ of the runoff overflowed from the infiltration facility.

Also, an analysis of the runoff that occurred during the monsoon season showed that $25 \%$ of the runoff overflowed through the storm sewer system of the urban area. These results show that the rainwater overflows after infiltrating the detention facility installed in the area during high-intensity rainfall of $100 \mathrm{~mm}$ or higher or when precipitation is $100 \mathrm{~mm}$ for $3 \sim 4$ days without the prior rainfall.

According to precipitation forecasts, torrential rainfall is becoming increasingly prevalent in Korea which is increasing the risk of floods. Therefore, the standards for storm sewer systems should be raised when planning and redeveloping urban areas, and not only should centralized facilities including sewer systems and rainwater pump facilities be increased, but a comprehensive plan should also be established for the water cycle of urban areas.

This study indicates that decentralized rainwater management can be effective in an urban area and also indicates that the extended application of rainwater infiltration systems can offer eco-friendly urban development.

(c) 2014 KIEAE Journal

\section{KEYW ORD}

Heavy rainfall,

decentralized rainwater management modular rainwater infiltration facility, reduced overflow

\section{A C C EPTA N CE IN FO}

Received April 10, 2014

Final revision received May 1, 2014

Accepted May 7, 2014

\section{Introduction}

\subsection{Background and Objectives of the Study}

Rapid changes and expansion of the urban areas resulted in the increase of impervious pavement. Because of this, the water circulation system of city faces problems and thus the importance of rainwater management are being discussed. Rainwater management stands at the center of the discussion in gear with damages by flooding to find a solution to the reduction of rainfall runoff. Studies are being carried out on BMP's (the Best Management Practices) or LID (Low Impact Development) technique as a possible plan for sustainable development and management of urban area.

BMP's and LID technique encompass all of hydrological aspects, environment and public amenity and are suggested as a comprehensive solution to planning, designing and managing rainwater treatment (CIRIA, 2001). This technique is also combined with conventional rainwater drainage system and suggested as an alternative that can endure the safety from urban

pISSN 2288-968X, eISSN 2288-9698 http://dx.doi.org/10.12813/kieae.2014.14.3.015 flooding and restore city water cycle.

The importance of water cycle structure and rainwater management was stressed in Urban Development Design Guideline (Ministry of Land, Transport and Maritime Affairs, 2009) in an attempt to establish low-carbon and green city. As a result, decentralized rainwater management plan is being experimentally introduced to South Korea. As the Ministry of Environment announced the guideline for the design and operation of rainwater facility, a rainwater management system that can realize more substantial water circulation. Keeping abreast with the development of urban areas, decentralized rainwater management system is being paid more attention as an approach to environment-friendly urban development and the importance is getting greater.

On the other hand, a number of casualties and damage to properties break out every year by rainfall, which is characterized with frequent local downpour and turning into flood in a very short time period. On the contrary, ground water depletes during drought season. In this respect, more efficient rainwater management is necessary to cope with diverse climate patterns. For example, the localized heavy rain that happened in 
the central region of Korea in July 2011 recorded the rainfall of $110.5 \mathrm{~mm}$ in almost 100 years and caused severe social casts such as casualties and damages to properties. The key reason for such massive social damages is the insufficient rainwater sewer system of the current management system, which can't cope with it (Industry- Academic Cooperation Foundation of Semmyung University, 2013).

After experiencing the fatal damages by typhoon in 2010, Seoul City was going to elevates the drainage capacity of main streets from 10-year flood frequency to 30-year flood frequency and construct accordingly (IS, Ko. 2011), but it turned out to be a huge cost. So the city government is constructing rainwater infiltration facilities together to increase the amount of infiltration of rainwater against sudden and intensive rainfall.

As mentioned above, it is necessary to prepare a new form of rainwater management system that can cope with localized heavy rain occurring mainly due to climate change. In preparing for it, economic feasibility, environmental impact and efficiency should be all considered. Also, it is better to avoid drainage through of rainwater sewerage system but induce rainwater to permeate through soil. The latter method is contributable to the restoration of urban environment.

In this consideration, the present study aims to develop rainwater infiltration system that can be applied to overall urban areas and attempts to analyze the effectiveness of the field planning and construction of the system upon flow reduction.

\subsection{Contents and Method of Study}

The contents and method of this study are as follows.

First, this study has developed flood-preventive rainwater management system that can secure urban safety against intensive rainfall and reduce the expansion of budge for the extension of sewage sewer management system. Taking into account the characteristics of land usage in urban areas, this study set a direction to system development and examined the operation mechanism by which safety and environment can be maintained by type of rainfall: general and heavy rainfall1).

Second, this study established an installation plan of the developed system and constructed it in the parking lot within the premise of Semyung University located in Jecheon City, Chungbuk Province, in order to analyze the flow reduction effect of the system.

Third, experiment was conducted and monitored in the construction site from September, 2012 to December, 2013 and the data was used to analyze the reduction effect.

\footnotetext{
1) According to it, trial product was modeled and unit design infiltration was
} calculated through the field infiltration facility. See YH, Han et al (2012).

\section{System Development}

\subsection{Development Direction and Operation Mechanism}

This study attempted to develop the system in a way that it can't only prevent damages from flood by holding it in underground temporarily during intensive rain and guiding it to permeate in through ground, but also contribute to store underground water. Placing in consideration the spatial conditions of the location to apply the system to, this study developed the system in module form to adjust to the increase and decrease of capacity.

The system was developed to be applicable to the road lines of urban area, which are usually characterized with a high density of land use to store and drain it without power in module type to increase or decrease capacity; and to overflow rainwater to secure safety from intensive rainfall.

The operation mechanism varies by precipitation type, as follows.

\section{(1) Normal Rainfall}

In case of normal rainfall, the runoff that occurs in road surface or the surface of parking lot is first purified when passing the filter media installed in the drain inlet. At that time, the pollutants in the initial rainwater are purified. The initially purified rainwater is stored in an underground structure temporarily. After that, the stored rainwater passes an infiltrative structure into soil, which helps store underground water.

\section{(2) Heavy Rainfall}

In case of heavy rainfall, increased runoff fills the underground structure. And then the rainwater passes through the overflow pipe, which is connected to existing urban rainwater pipe, into the urban rainwater pipe. Therefore, when it rains heavily, rainwater surpassing the capacity of the underground storage is discharged into the urban rainwater pipe, so the developed system can reduce peak flow volume as well as peak flow time by letting rainwater keep passing through.

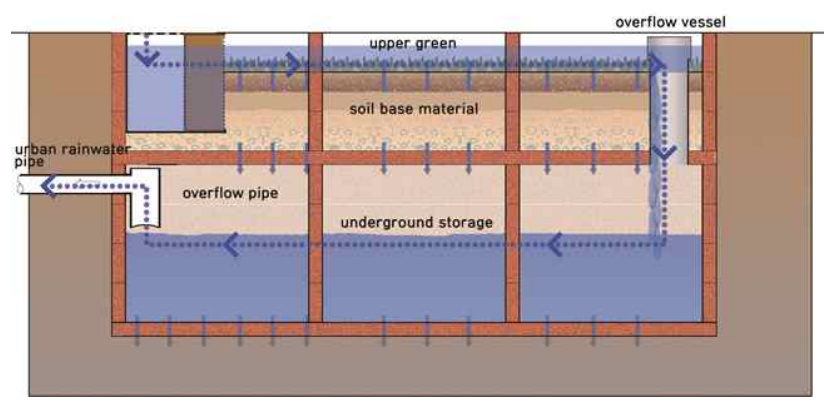

Fig. 1. How it works the decentralized Rainwater management 


\subsection{System Composition and Application}

\section{(1) System Composition}

This system consists of underground storage, overflow vessel, overflow pipe and urban rainwater sewage system. The form and function of each component are as follows.

First, underground storage holds down rainwater on top temporarily and let it pass through at a certain time interval. Besides, it is structured strong enough to sustain the weight of the upper structures. It is developed in cell-based type to control holding capacity to fit the conditions of the location to apply it to. Therefore, it is possible to increase and decrease capacity by adjusting the number of piling layer.

The cell-based unit of this system can not only be vertically layered but also be assembled horizontally in a linear form. Depending on the number of lateral connection, it is possible to increase or decrease the horizontal capacity. Since this underground structure is of infiltration, it can hold in purified rainwater that permeates from the top and discharges it into base ground.

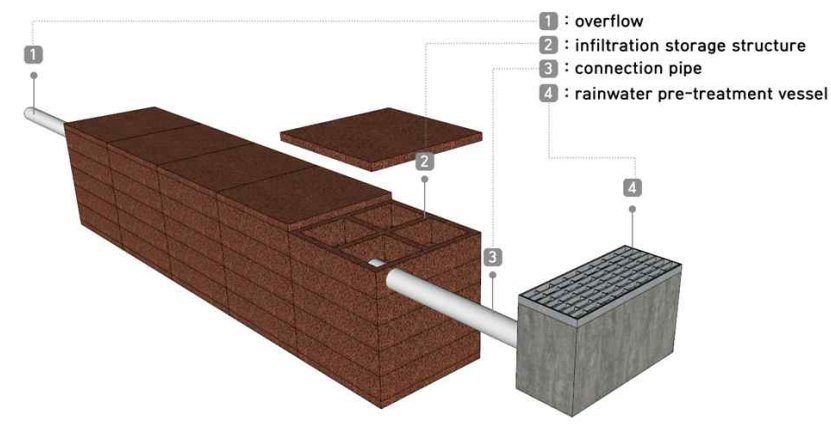

Fig. 2. The configuration of the developed system

Second, the rainwater pre-treatment vessel can be installed in place of street inlet installed the lateral ditch of a road in general. It is designed to purify initial rainwater. The rainwater pre-treatment vessel consists of impurity holder, sediment holder and filter media box in it.

Third, there are connection pipe and overflow pipe. The connection pipe is for the purified rainwater in the pre-treatment vessel to enter underground storage. The overflow pipe functions to discharge overflowed rain water during heavy rainfall into urban rainwater sewage system.

\section{(2) System Application}

Rainwater management system that is generally applied in urban areas is as follows. Rainwater runoff from the roof surface of a building enters into a collecting well through a rainwater gutter and the rainwater collected here drains through a rainwater duct. Road runoff is also collected in a lateral ditch and drain into a rainwater duct installed in the center of the road. This system can drain all of rainfall runoff when it rains less than $10 \mathrm{~mm} / \mathrm{h}$ as well as there is heavy rain. Therefore, it tends to lower the level of ground water level (Figure 3, right).

On the other hand, when a linear infiltrative rainwater storage facility is installed under the sidewalk in roadside, as shown in Figure 3 left, it can store road runoff and sidewalk runoff temporarily and let it pass slowly. For the reason, it can be effective for intensive and heave rain. Furthermore, it can drive even a little of rainwater into soil, so that we can expect environmentally favorable effect such as securing underwater level of urban areas and preserving soil ecosystem.

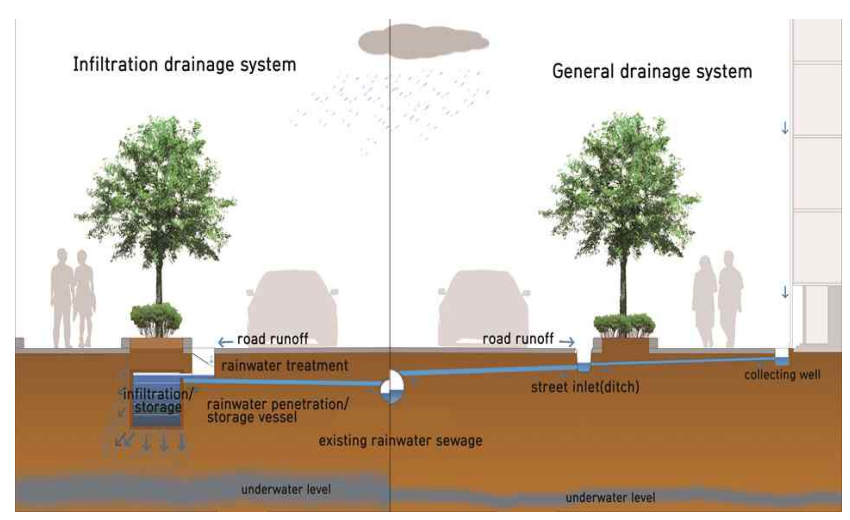

Fig. 3. Application examples of developed system on the roadside (left) and the general drainage system in roads (right)

\section{Planning and Construction}

\subsection{Spatial Application Plan}

To analyze the performance of the developed system, this study designed an application plan to a certain space and constructed the site. The parking space and the green area in Semyung University (Jecheon City in Chungbuk Province, South Korea) were chosen for the test. Besides the decentralized rainwater infiltration/storage facility developed for the present study, this study remodeled an underground structure, which had been used as septic tank in the research area before, for a rainwater tank and connected the tank to the rainwater infiltration facility. In other words, it intended to discharge overflowed rainwater from the rainwater tank into the rainwater infiltration facility and overflowed rainwater from this facility into an urban rainwater sewage2). (See Figure 5).

2) In construction, we remodeled the previously used septic tank into a rainwater storage tank and connected to the tank a pile line that collects rainwater flowing down from the roof surface. However, since a pipe line work that enables to use 


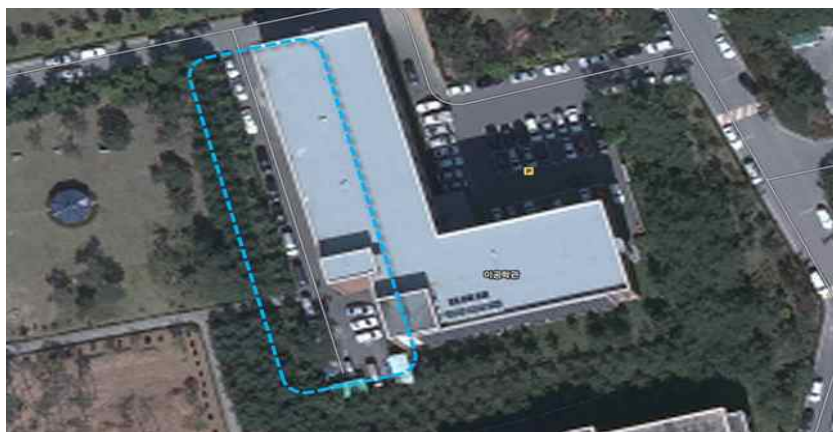

Fig. 4. The Status of the application site in Semyung Univ.

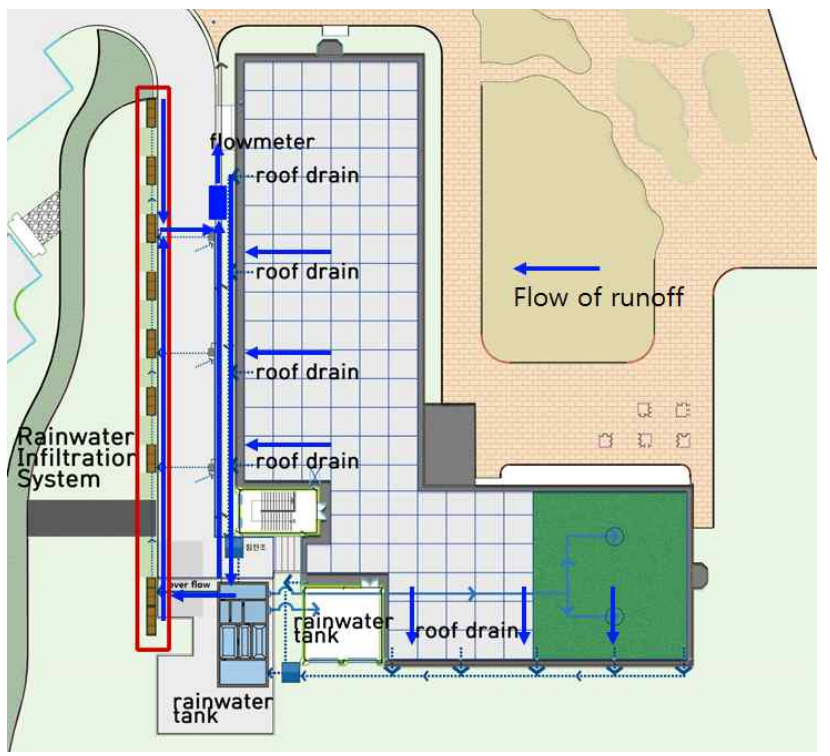

Fig. 5. Rainwater Management plan in site

The area of rainwater gathering was total $1,539 \mathrm{~m}^{2}$ combining the area of the roof and the external space and the infiltration/storage vessel had a capacity of 27 tons ${ }^{3}$.

\subsection{System Construction}

The construction of the system followed this order: ground work (bed excavation) $\rightarrow$ rubble arrangement $\rightarrow$ installation of facility $\rightarrow$ installation of connection pipeline (duct) $\rightarrow$ installation of flowmeter $\rightarrow$ pavement $\rightarrow$ finish work.

First, ground was excavated and rubbles were arranged.

The ground was dug deeper by 1 meter than the height of the infiltration/storage vessel and rubbles on the base were arranged.

Second, cover the rainwater infiltration/storage facility made of modules with non-woven cloth (or felt) and installed under the ground. After an access hole was prepared for $\mathrm{m}$

onitoring system, the ground was filled.

rainwater for toilet water in the structure, the runoff reduction by recycling stored rainwater had to be excluded from the scope of the study.

3) This system is a modular infiltrating storage facility and can increase or decrease its capacity depending on the location of installation. One cell is as big as $1 \times 1 \times 1 \mathrm{~m}$. A total of 9 sets ( each set consists of 3 cells) were installed in the system in the field with handling capacity of 27 tons (See Figure 5).
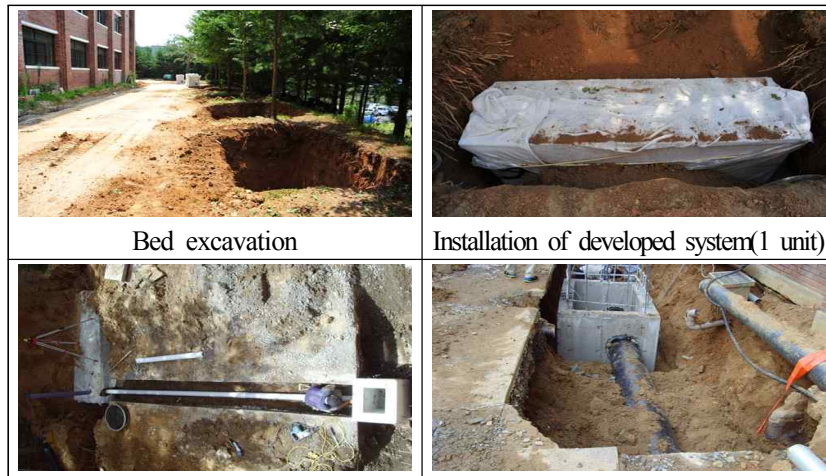

Installation of developed system(1 unit)

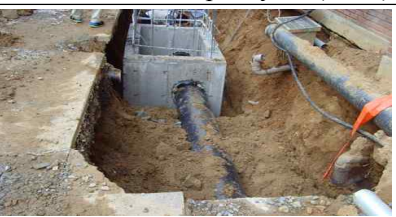

Installation of Pipeline
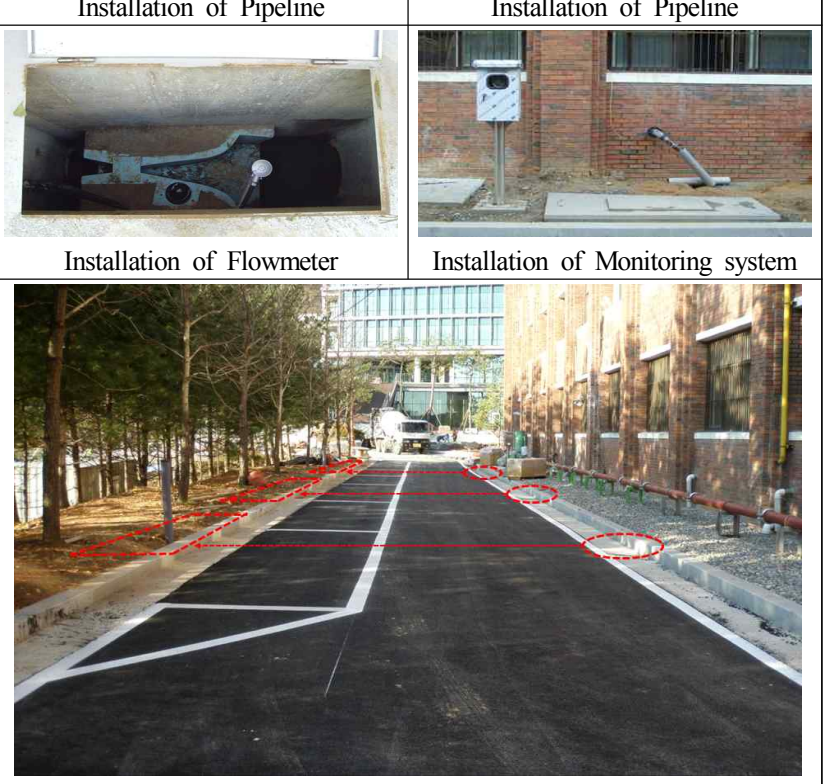

status after construction

Fig. 6. Construction process in sites and status after construction

Third, install a collecting well connected to the rainwater gutter of the roof surface and then a pipeline that connects between the infiltration system and the collecting well.

Fourth, a flowmeter was installed in the final outlet of the facility. And the amount of overflowed rainwater was measured in the target area.

\section{Analysis of runoff reduction Effect}

\subsection{Monitoring Items and Methods}

The flowmeter used in this study measures instantaneous flux and accumulated flux. Accumulated flux was monitored every day to calculate daily flow rate.

For the data of rainfall, daily rainfall (from September 2012 to December 2013) of the weather station was used.

The amount of runoff in the research area was calculated as follows.

$Q=P \times A \times e \times 10^{-3}$

(Formula 1) 
Q: flow $\left(\mathrm{m}^{3}\right)$. P: precipitation $(\mathrm{mm})$,

A: area of rainwater collection $\left(\mathrm{m}^{2}\right), \mathrm{e}$ : runoff coefficient

\subsection{Monitoring Results}

\section{(1) Yearly Monitoring Results}

The period from September 2012 to December 2013 is that in which stable values could be obtained after the installation of flowmeter and pilot test.

Rainfall from September to December 2012 was 230mm and total 318 tons of runoff occurred. Of them, it was turned out that $22 \%$ or 70 tons were overflowed to a public rainwater sewage system (see Figure 7).

Key daily rainfall is as follows.

On September 28, 2012, the rainfall was a total of $13.5 \mathrm{~mm}$ and runoff of $18.7 \mathrm{~m}^{3}$ occurred. But there was no overflowed rainwater monitored by the flowmeter. On the other hand, it recorded $39.5 \mathrm{~mm}$ of rain on October 22, 2012 and a lot of $54.7 \mathrm{~m}^{3}$ ran off. And on $23^{\text {rd }}$ and $24^{\text {th }}$ of the same month, $11 \mathrm{~m}^{3}$ and $18.8 \mathrm{~m}^{3}$ were monitored to have overflowed, respectively. In addition, about 60 tons of turned out to have run off on $24^{\text {th }}$ of October when there was rainfall of $44 \mathrm{~mm}$ and a total of 30 tons of rainwater had overflowed between $27^{\text {th }}$ and $28^{\text {th }}$ of the same month (see Table 1).

Table 1. The results of Monitoring in 2012

\begin{tabular}{c|c|c|c}
\hline date & Precipitation $(\mathrm{mm})$ & runoff $\left(\mathrm{m}^{3} /\right.$ day $)$ & overflow $\left(\mathrm{m}^{3} /\right.$ day $)$ \\
\hline $2012-10-22$ & 39.5 & 54.71 & 0 \\
\hline $2012-10-23$ & 0 & 0 & 11.61 \\
\hline $2012-10-24$ & 0 & 0 & 18.80 \\
\hline $2012-10-25$ & 0 & 0 & 0 \\
\hline $2012-10-26$ & 0 & 0 & 0 \\
\hline $2012-10-27$ & 44 & 60.94 & 26.39 \\
\hline $2012-10-28$ & 0 & 0 & 3.80 \\
\hline
\end{tabular}

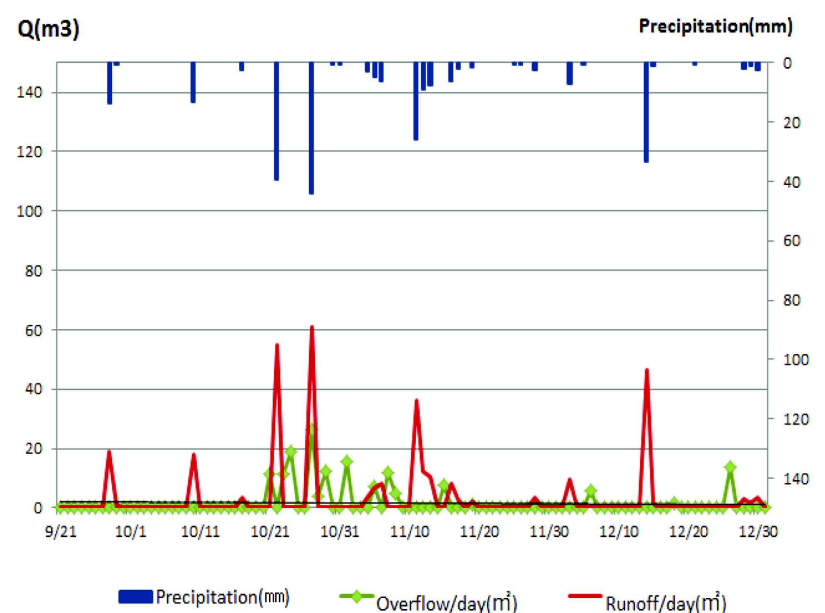

Fig. 7. Outflow reduction in the testbed(2012. 9-2012.12)
Although it was difficult to accurately analyze runoff time and peak flow volume by rainfall pattern, it was confirmed that there was runoff reduction effect to some extent ${ }^{4)}$. Judging from these results, it was analyzed that about $45 \%$ to $50 \%$ of rainfall overflows when it rains more than $40 \mathrm{~mm}$.

Figure 8 shows the monitoring results from January the $1^{\text {st }}$ to December the $31^{\text {st }}$, 2013. Over the year 2013, the total rainfall was $1,386 \mathrm{~mm}$ and a total of 1,918 tons overflowed in the catchment area. Of them, a total of 410 tons were overflowed as monitored by flowmeter, and it takes $20.5 \%$ of the total runoff.

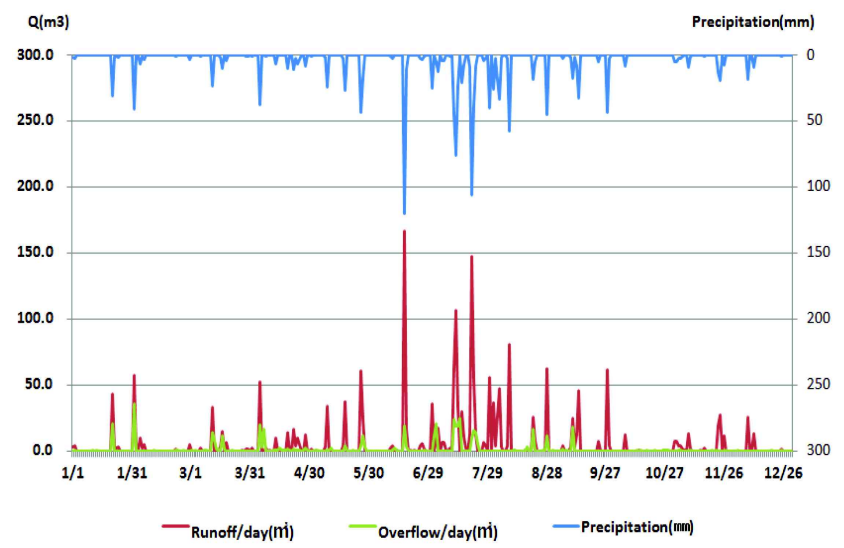

Fig. 8. Outflow reduction in the test-bed(2013.01-2013.12)

\section{(2) Rainfall during Summer Season}

This study analyzed the rainfall between June $15^{\text {th }}$ and July $24^{\text {th }}, 2013$ to know about the runoff reduction of the developed facility during summer heavy rain season 5 ).

During this period, total precipitation was $534 \mathrm{~mm}$ and a total of 740 tons ran off to the catchment area. Of them, the flowmeter showed that a total of 185 tons were overflowed, which takes $25 \%$ of the total runoff (Figure 9).

On June 18, 2013, rainfall of $120 \mathrm{~mm}$ fell in the concerned region and about 166 tons of runoff occurred. Of them, 19 tons of rainwater were measured to have overflowed by the flowmeter. During 20 days of rainfall, from May $29^{\text {th }}$ to June $18^{\text {th }}$, a great deal of rainwater infiltrated into soil because there was no preceding rainfall. In addition, it was likely that much more rainwater flowed over outsides along with the surface of paved roads due to heavy rainfall as well as through the manhole where the flowmeter was installed. Therefore, it is assumed that more than 19 tons, which was measured by the flowmeter, of rainwater

4) On October $22^{\text {nd }}, 2012$, precipitation of $4 \mathrm{~mm}$ was recorded but the flowmeter measured about 30 tons of overflow in the facility throughout $23^{\text {rd }}$ and $24^{\text {th }}$. In the meantime, $44 \mathrm{~mm}$ of rain was recorded on October $27^{\text {th }}$ and about 30 tons of rainwater overflowed throughout the day and the following day. Although the pattern of rainfall couldn't be confirmed by time of rainfall, it was known that the facility has runoff reduction effect to some degree.

5) Because The monitoring data of this study shows instantaneous and accumulated flux and only the data of the latter were available, no analysis wasn't attempted on the change and time of peak flow volume. 
flew into rainwater sewage system. As noted, it seems possible to guide rainwater flow into the infiltration facility open area as planned in case of small amount of rainfall. However, when there is heavy rain, the phenomenon was observed that rainwater ran off outsides rather than into the collecting wall.

In the meantime, precipitation of $106 \mathrm{~mm}$ was recorded in a day on July $22^{\text {nd }}$ when even electricity cut off. Therefore, no accurate measurement was possible on that day. In this respect, it was learned that emergency electrical system is worth considering for monitoring facility in case of cloudburst during summer season.

Table 2. The results of Monitoring during strong rainfall in 2013

\begin{tabular}{|c|c|c|c|}
\hline date & Precipitation(mm) & runoff( $\mathrm{m}^{3} /$ day $)$ & overflow( $\mathrm{m}^{3} /$ day) \\
\hline 2013-06-15 & 0 & 0.0 & 0.0 \\
\hline 2013-06-16 & 0 & 0.0 & 0.0 \\
\hline 2013-06-17 & 0 & 0.0 & 0.0 \\
\hline 2013-06-18 & 120 & 166.2 & 19.1 \\
\hline 2013-06-19 & 11.5 & 15.9 & 3.1 \\
\hline 2013-07-12 & 0.5 & 0.7 & 0.0 \\
\hline $2013-07-13$ & 45.5 & 63.0 & 23.7 \\
\hline 2013-07-14 & 76.5 & 106.0 & 18.9 \\
\hline 2013-07-15 & 23.5 & 32.5 & 18.5 \\
\hline 2013-07-16 & 0 & 0.0 & 25.0 \\
\hline 2013-07-17 & 21.5 & 29.8 & 0.0 \\
\hline 2013-07-18 & 7.5 & 10.4 & 0.0 \\
\hline 2013-07-19 & 1.5 & 2.1 & 0.0 \\
\hline $2013-07-20$ & 0 & 0.0 & 0.0 \\
\hline 2013-07-21 & 9.5 & 13.2 & 0.0 \\
\hline $2013-07-22$ & 106.5 & 147.5 & 10.0 \\
\hline $2013-07-23$ & 39.5 & 54.7 & 15.7 \\
\hline $2013-07-24$ & 8.5 & 11.8 & 14.2 \\
\hline $2013-07-25$ & 0 & 0.0 & 5.4 \\
\hline
\end{tabular}

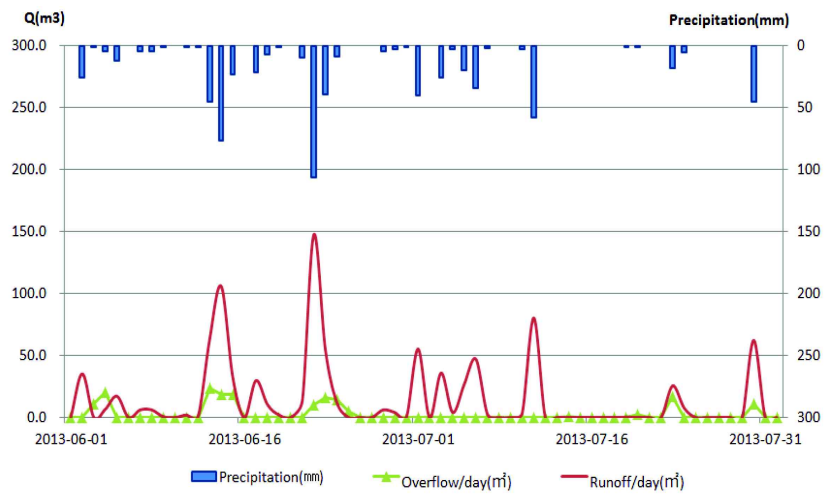

Fig. 9. Outflow reduction in the testbed(2013. 06-2013.07)

Although the ratio of overflow to the total runoff in 2013 was accurately measured to be $20 \%$, the system of this study couldn't gauge the amount of overflow when precipitation is more than $100 \mathrm{~mm}$. According to the measurement of 2012, however, $40 \%$ to $50 \%$ of total runoff flowed over when there was more than $40 \mathrm{~mm}$ of rainfall on daily base. Therefore, it can be estimated that more than the figure of overflow is possible when daily precipitation is over $100 \mathrm{~mm}$.

\section{Conclusion}

In this study, a rainwater infiltration system was developed to cope with localized rainfall by climate change and to universally apply to urban areas. In addition, the runoff reduction effect of the system was analyzed with a real spatial application.

The findings of the study are summarized as follows.

First, the developed system can be applied to urban areas of dense land use, especially to the road lines. The system is characterized with no power storage, module-based system to increase or decrease capacity and overflow facility to secure safety from intensive rainfall. When it is installed under a sidewalk, it can store road runoff and sidewalk runoff temporarily and let it infiltrate slowly. For the reason, it can be effective in preventing damage from flood. Furthermore, since it can even infiltrate a small amount of rainwater into soil, we can expect environmentally favorable effect such as securing underwater level of urban areas and preserving soil ecosystem.

Second, this study established an installation plan of the developed system and constructed it under the parking lot within the premise of Semyung University located in Jecheon City, Chungbuk Province, in order to analyze the flow reduction effect of the system. The area of rainwater gathering was total 1,539 $\mathrm{m}^{2}$ combining the area of the roof and the external space and the infiltration/storage vessel had a capacity of 27 tons. In the construction, a flowmeter was installed in the final outlet of the infiltration facility to monitor water flow and the amount of overflow was measured.

Third, the analysis of runoff reduction effect by using rainfall data (from September, 2012 to December, 2013) of the target area and actually measured data demonstrated that about $20 \%$ to $25 \%$ of the total runoff overflowed from the infiltration facility. In addition, the overflow analysis between June and July showed that $25 \%$ of total precipitation flowed over. However, when these data were compared with those of 2012 , about $40 \%$ to $50 \%$ of total runoff flowed over when daily precipitation was more than $40 \mathrm{~mm}$ and so it is expected that the figure will get greater when it rains move than $100 \mathrm{~mm}$ on daily base, though the latter couldn't be measured precisely. Therefore, it is necessary to prepare more accurate monitoring devices during summer heavy rain season6).

According to future weather forecast, the average temperature will keep rising in Korean Peninsula due to the increase of

6) Nonetheless, it can be said that it is very effect way to manage rainwater in consideration that daily rainfall is lower than $20 \mathrm{~mm}$ for 346 days, except 20 days, in a year except. 
greenhouse gas and thus there will be more chance of heavy rain. Likewise, it is warned that there will be more risk of flood. In this situation, it is needed to establish a more comprehensive urban water circulation plan as well as elevate the planning criteria of rainwater sewage system and expand centralized water management facilities such as rainwater storage and pumping stations while we redevelop urban areas and establish a plan of rainwater storage and maintenance. In this study, we have known that a decentralized rainwater management can be effective in local background and the expanded application of rainwater infiltration facility can contribute to developing environmentfriendly urban areas.

\section{Acknowledgements}

This work was supported by the Korea Agency for Infrastructure Technology Advancement grant funded by Ministry of Land, Infrastructure, and Transport.(R\&D/11 Advanced Urban 07).

\section{References}

[1] DJ Leggett et al 4, Rainwater and gray water use in buildings: decision-making for water conservation, CIRIA 2001.

[2] Ko, IS. 2011, A improve measures for flood safety net to respond to climate change, The Second Debate with Citizens for flood prevention Policy. The Metropolis of Seoul.

[3] Ministry of Land, Transport and Maritime Affairs. 2009. Urban Planning Guidelines to low-carbon green city.

[4] Semyung Univ.(2013), A Study on Rainwater Management System to respond to Climate Change in Urban Area. Korea Agency for Infrastructure Technology Advancement.

[5] Han, YH. Lee, TG. 2012. Estimation of Appropriate Infiltration Rate and the Effects of the Flowerbed type Infiltration System. Journal of the Korean Institute of Landscape Architecture, vol 40(5). 